\title{
FURTHER EXPERIENCE WITH INTERMITTENT CATHETERISATION
}

\author{
By J. J. Walsh, M.D. \\ National Spinal Injuries Centre, Stoke Mandeville Hospital, Aylesbury, Bucks.
}

AFTER publication of the important paper by Guttmann and Frankel in 1966 on the value of intermittent catheterisation in the early management of traumatic paraplegia and tetraplegia, the principles described by them were continued under similar conditions and applied to the same type of patient at the National Spinal Injuries Centres at Stoke Mandeville Hospital.

Their paper covered an II-year period up to 3I December I964 and this paper covers the period from I January I965 to 3I December I 966.

\section{MATERIAL}

During these two years I2I traumatic lesions (I05 male and I 6 female) were admitted to the Centre within I4 days of injury. Seven cases, all male, have been

\section{TABLE I \\ Total Material}

Traumatic Lesions admitted within I4 Days of Injury between I.I.65 and 3I.12.66

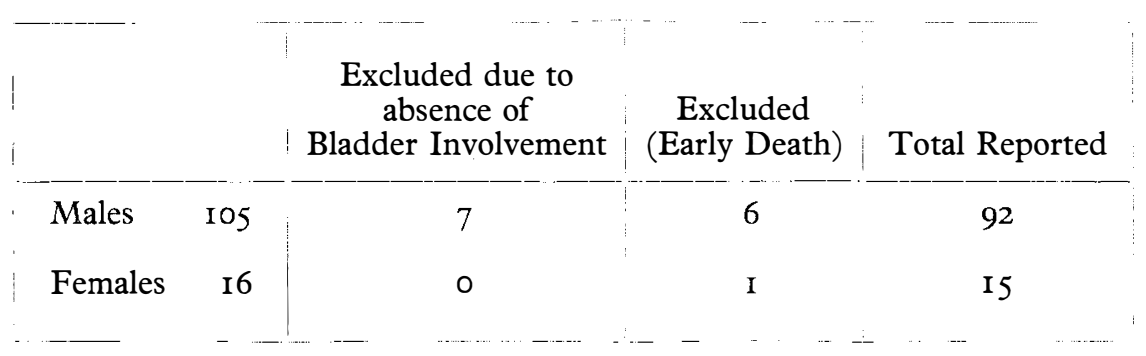

excluded from the series, because the degree of bladder involvement was considered too minor to warrant inclusion. In addition, seven cases (six male and one female) were excluded because they died in the early weeks after injury from causes other than urological complications. This left 92 male and 5 female cases in the series. The majority of the cases (60) were admitted within 48 hours of injury, and the advantage of early admission to a special unit is reflected in the fact that 95 out of 107 cases had sterile urine on admission. The ages of the cases varied between 4 and 68 for females (average age $28 \cdot 3$ years) and 12 and 74 for males (average age $28 \cdot 7$ years).

\section{METHOD}

The differences between the method described in the paper of Guttmann and Frankel and the method used in this series were (I) all intermittent catheteri- 
sation carried out on male cases was done by a medical officer as before but using packaged equipment sterilised in a central sterile supply department (autoclaved), and the catheters were lubricated before sterilisation, thus reducing the risk of contamination. (2) As a direct result of the findings of Guttmann and Frankel the female cases were in the majority of instances catheterised by a medical officer. (3) More intensive and more sustained treatment with antibiotics and other medicaments including G.500 was carried out in those cases which developed infection.

\section{RESULTS}

Females (Table II). The number of females (I5) studied is too small to allow significant conclusions but it is interesting that Io cases (67 per cent.) were admitted with sterile urine and Io cases (67 per cent.) were discharged with sterile urine.

\section{TABLE II}

Females

Neurological Lesion and Sterility on Admission and Discharge

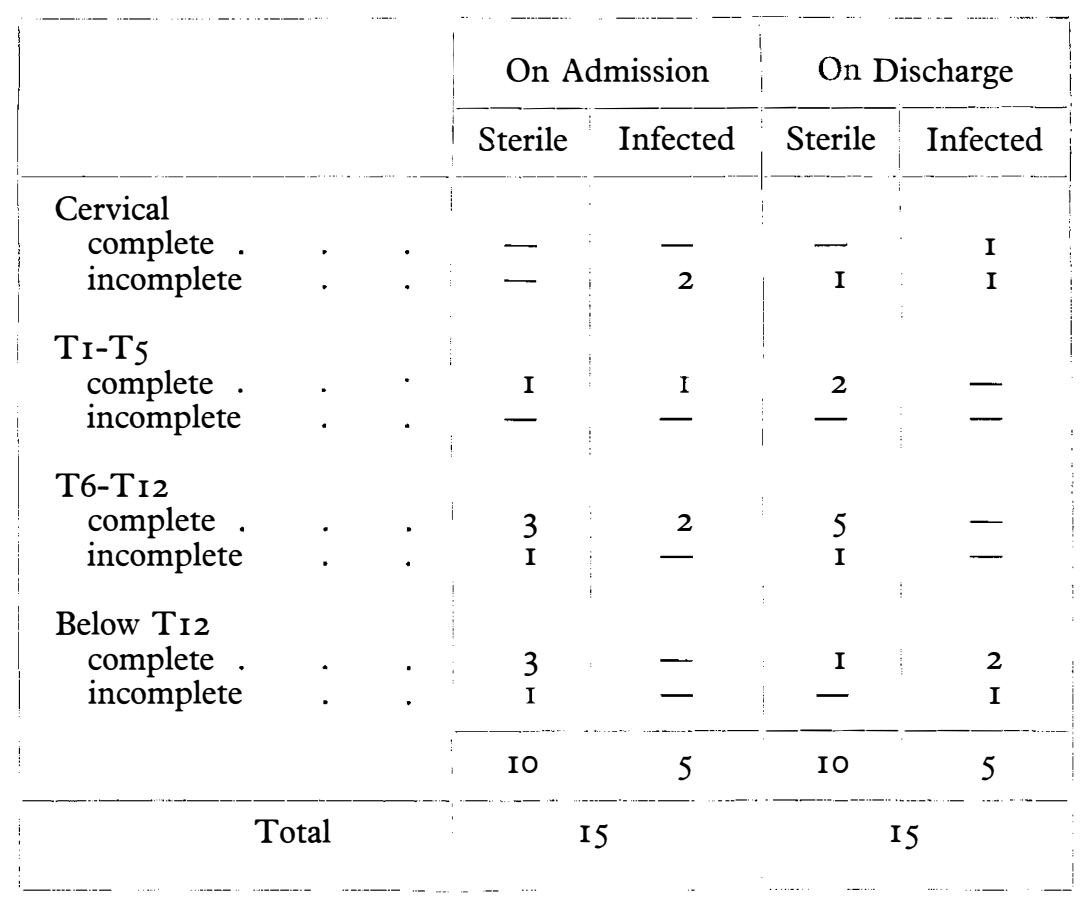

Sterile on admission, Io $(67 \%)$. Sterile on discharge, Io $(67 \%)$

Males (Table III). Of the 92 cases studied $85(92 \cdot 4$ per cent.) were admitted with sterile urine, and $76(82 \cdot 6$ per cent.) were discharged with sterile urine.

It is regretted that to date follow-up examinations have been carried out on only 7 female cases and 54 males. These showed six sterile and one infected in 
the females and 39 sterile and 15 infected in the males. The time of follow-up averaged 7 months for females and 12 months for males.

The incomplete records of follow-up examinations are due to the facts that many of the cases were discharged fairly recently and because of pressure of work routine check-ups, especially of sterile cases, are often carried out later than is desirable. For the same reason more cases are now being referred to other units for routine check-ups. It is hoped to improve this in the future by better integration and an expansion of the paraplegic service in Britain.

\section{TABLE III}

Males

Neurological Lesion and Sterility on Admission and Discharge

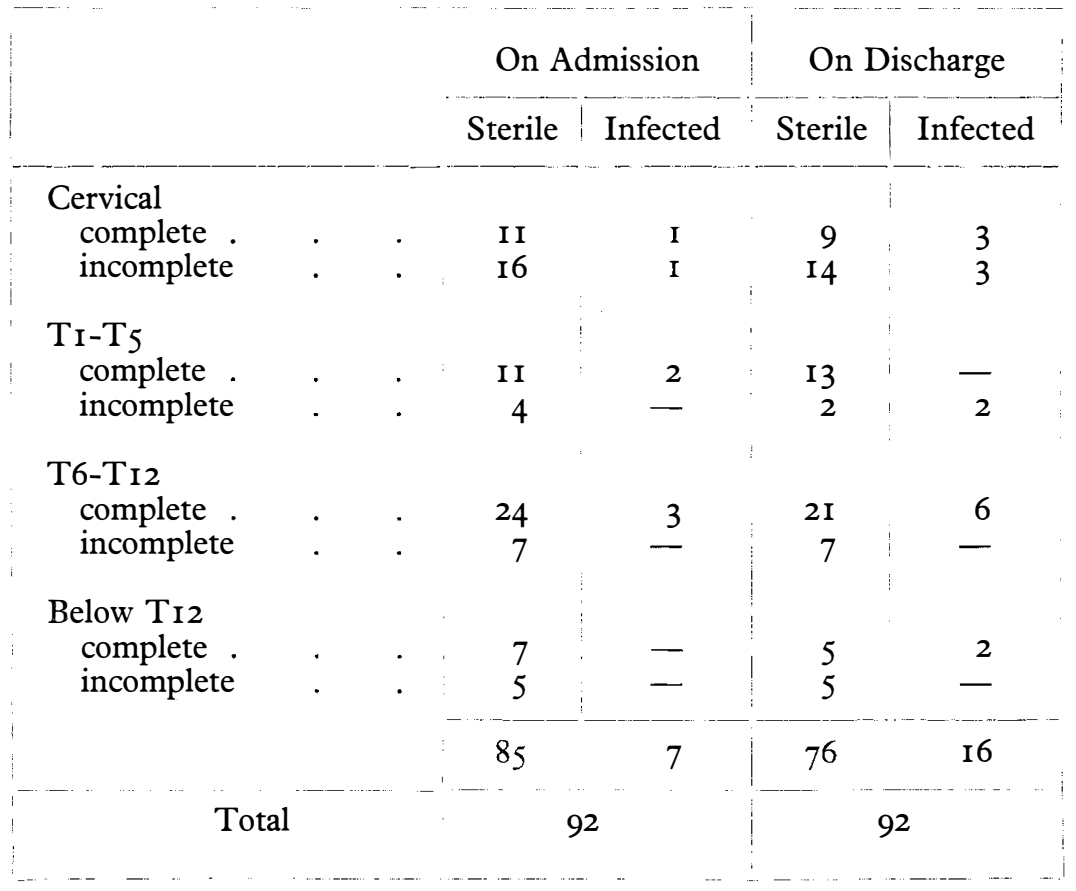

Sterile on admission, $85(92 \cdot 4 \%)$. Sterile on discharge, $76(82 \cdot 6 \%)$

\section{COMPLICATIONS}

Vesico-ureteric Reflux. Out of the 107 cases, there were nine cases of reflux, all male, of which five were treated by indwelling catheter and were all infected on follow-up. The remaining four cases are sterile and under regular observation for possible renal deterioration.

Stone Formation. Only one case was found to have a stone in the urinary tract-a male with left renal calculus, who also showed a bilateral vesico-ureteric 
reflux. The stone was removed surgically and the patient discharged with sterile urine and mild degree of hydronephrosis on the left side.

Bladder Neck Resection. Four cases required bladder neck resection to establish adequate micturition. Three were complete lesions between T6 and T2, and one was an incomplete lesion below C5. Two were discharged with sterile urine and two with infected urine.

\section{DISCUSSION}

The high rate of sterility in males on admission (92 per cent.) was related to the large number admitted early but the sterility rate was also high in many of the cases admitted after several days. This is largely due to the fact that the majority of these cases had been treated before admission with an indwelling Gibbon catheter. From the material studied in this series it was an obvious conclusion that if an indwelling catheter must be used as the initial treatment in traumatic spinal cord injuries then the Gibbon catheter is far preferable to the Foley type catheter, whether latex or plastic. Using the Gibbon catheter is likely to ensure sterility for several days (Cosbie Ross). Nevertheless, it is not in the writer's opinion as satisfactory a method of treatment in recent injuries as intermittent catheterisation, (a) because eventual infection is practically inevitable and (b) as with all indwelling catheters it produces trauma to bladder mucosa. This latter effect is indicated by the number of cases so treated who develop haematuria and even more strikingly by the cystoscopic appearances. On the relatively few occasions on which the writer has carried out cystoscopy on sterile bladders in recently injured cases it was quite startling to see the localised area of submucosal haemorrhage with surrounding hyperaemia and oedema in those cases who had had indwelling catheters for the first time, sometimes for only a day or two.

Among the 76 male cases discharged with sterile urine, only 15 had never shown even a technical infection on microscopy and culture. Most had shown transient infections without clinical symptoms, but quite a number had clinical infections on one or more occasions during the initial period of bed rest and a smaller number had shown persistent infections for several weeks which eventually responded to medication.

The value of treating infection as early as possible, even before bacteriology reports are available, was demonstrated repeatedly.

The improvement in sterility rate in this series as compared with that of Guttmann and Frankel appears to be related to four main factors :

I. A somewhat higher rate of sterility on admission.

2. Improvement of technical aspects of catheterisation, particularly the use of individual autoclaved catheter packs. (Since completion of this paper autoclaved packs have been brought into use in the female ward.)

3. More persistent use of antibiotics and other medicaments.

4. Catheterisation of female patients by a skilled medical officer. 


\section{SUMMARY}

92 male and I5 female cases of spinal cord injury were admitted to the National Spinal Injuries Centre at Stoke Mandeville Hospital within I4 days of injury between I January I965 and 3I December 1966. All the cases were treated by intermittent catheterisation at the Centre and the results, with particular regard to permanent sterility, are described. Views are expressed on the probable reasons for the improvement in the results of treatment by intermittent catheterisation in this series as compared with that of Guttmann and Frankel.

\section{REFERENCE}

Guttman, Sir L. \& Frankel, H. (I966). Int. F. Paraplegia, 4, 63. 